CIUDAD Y TERRITORIO

ESTUDIOS TERRITORIALES

ISSN(P): 2697-231X; ISSN(E): 2697-2328

Vol. LIII, N.ํMonográfico 2021

Págs. 101-118

https://doi.org/10.37230/CyTET.2021.M21.06

CC BY-NC-ND

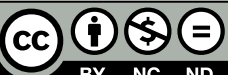

\title{
Desigualdad, renta familiar y políticas de vivienda en Bilbao
}

\author{
José Enrique Antolin-IrIA ${ }^{(1)}$ \\ Amaia IZAOLA-ArgüESO (2)
}

(1) Profesor Titular. Universidad del País Vasco (2) Profesora Titular Interina. Universidad del País Vasco

RESUMEN: Si bien la renta familiar de los hogares bilbaínos ha crecido en su conjunto durante el periodo 2001-2017, han sido las rentas más altas las que se han visto especialmente favorecidas, aumentando, así, la distancia económica y social con respecto a los hogares de renta media y baja. Esto ha generado un modelo de crecimiento de ciudad dual, generando así una distancia económica y social, que también ha tenido un reflejo en el espacio urbano y en los barrios que configuran la ciudad de Bilbao. En este contexto, las políticas de vivienda desarrolladas por las diversas administraciones públicas durante este periodo tuvieron como objetivo crear una base social de propietarios, más que resolver el problema habitacional de aquellos colectivos con mayor necesidad de vivienda, lo que contribuyó a la construcción de este modelo de crecimiento urbano dual.

PALABRAS CLAVE: Renta familiar; Desigualdad; Política de vivienda; Población desfavorecida; Ciudad dual.

\section{Inequality, family income and housing policy in Bilbao}

ABSTRACT: Although household income in Bilbao rose overall from 2001-2017, it was mainly the higher-income brackets that benefited most, thereby increasing the economic and social distance between them and those in the middle and lower-income brackets, and generating a dual growth model. This economic and social distance is reflected also in the urban space and districts that make up the city of Bilbao. Within this context, the housing policies implemented by the different public administrations between 2001 and 2017 were targeted more at creating a social base of home-owners than at solving the housing problems of those groups most in need, thereby contributing to the consolidation of this dual model of urban growth.

KEY WORDS: Family income; Inequality; Housing policy; Disadvantaged population; Dual city.

Recibido: 06.07.2020; Revisado: 15.10.2020

Correo electrónico: joseenrique.antolin@ehu.eus; N. ${ }^{\circ}$ ORCID: https://orcid.org/0000-0002-0028-0888

Correo electrónico: amaia.izaola@ehu.eus; N. ${ }^{\circ}$ ORCID: http://orcid.org/0000-0002-3432-9037

Los autores agradecen los comentarios y sugerencias realizados por los evaluadores anónimos, que han contribuido a mejorar y enriquecer el manuscrito original. 


\section{Introducción ${ }^{1}$}

lo largo del periodo 2001-2017 se han producido diferentes transformaciones en el espacio urbano de Bilbao, generando lo que podemos considerar como una ciudad dual, consecuencia de un crecimiento igualmente dual. Entendemos esta dualidad, siguiendo a CASTELLS (1991), como una ciudad que presenta una estructura socioespacial estratificada y formada principalmente por dos espacios: uno de ellos, relacionado con el polo dinámico de crecimiento de las rentas, mientras que el otro polo presenta un espacio con una población con rentas bajas y escasas posibilidades de movilidad social ascendente.

Con la finalidad de poder abordar este análisis socioespacial de Bilbao y sus barrios, hemos estructurado este trabajo en función de tres ejes que están estrechamente interconectados, y que nos servirán para dar respuesta a las características de la dualidad de Bilbao y sus barrios. En el primer eje partimos del análisis de la evolución que han tenido las rentas familiares a lo largo del periodo 2001-2017, así como a las tipologías de rentas familiares con las que cuentan los hogares ${ }^{2}$. En este caso, nos encontramos con cinco tipos de rentas en los hogares según su procedencia, y que los van a definir en cierta medida: a) las rentas procedentes de la actividad laboral, por lo tanto del salario, o "rentas de trabajo"; b) aquellas rentas procedentes de las plusvalías generadas por los ahorros financieros de la familia (beneficios generados por las acciones, intereses bancarios...) o "rentas de capital mobiliario", c) rentas procedentes de propiedades inmuebles (alquileres de casas, garajes, venta de parcelas...), es decir, las "rentas de capital inmobiliario", d) recursos económicos que proceden del ejercicio de profesionales

\footnotetext{
11 Este artículo forma parte de la investigación financiada por el Ministerio de Economía, Industria y Competitividad (2017) (CSO2017-83968-R), que lleva por título "Influencia de los cambios de régimen de producción y acceso a la vivienda sobre la restructuración social de las grandes ciudades españolas".

${ }^{2}$ La fuente de información empleada ha sido la estadística de Renta personal y familiar publicada por el Instituto Vasco de Estadística (EUSTAT, 2019), ya que la información obtenida es censal, no se hace a través de entrevistas como la encuesta de Condiciones de Vida del INE, sino a través de las declaraciones de renta del conjunto de los contribuyentes, así como los datos aportados por las diversas administraciones, especialmente las Diputaciones Forales. Asimismo, el nivel de desagregación de los datos es mayor al incluir las rentas de trabajo, rentas de capital mobiliario e inmobiliario, de actividades y de transferencia. Las declaraciones de la renta familiar se desagregan por barrios y, por último, las series de datos comienzan en el 2001, se realizan
}

liberales y/o del trabajo autónomo, o "rentas de actividades"; e) y finalmente, las "rentas de transferencias", es decir, aquellos ingresos que proceden directamente del Estado en forma de pensiones, ayudas sociales, subsidio de desempleo o renta de garantía de ingresos, entre otras $^{3}$.

En cuanto al segundo eje que presentamos, nos centramos en la descripción sociodemográfica de los barrios que configuran el espacio urbano de Bilbao que, previamente, han sido clasificados en función del nivel de ingresos de las familias que habitan en ellos. $Y$ finalmente, abordamos el modelo de crecimiento dual de la ciudad, consecuencia de la evolución de estas rentas familiares, así como de las políticas de vivienda que se han desarrollado desde el Gobierno Vasco (GV) y las consecuencias que dichas políticas han tenido en la ciudad. Es en este contexto, es importante conocer los criterios de acceso a las Viviendas de Protección Oficial (VPO), y las políticas públicas de alquiler como alternativa a la propiedad.

\section{La estructura de la renta familiar en los hogares de Bilbao y su distribución espacial (2001-2017)}

Entender las rentas familiares de los hogares ayuda a comprender los procesos de desigualdad. En este artículo tenemos en cuenta los ingresos de las rentas familiares, no así cómo estas son gastadas ${ }^{4}$.

Con la finalidad de poder abordar este análisis, hemos partido de tres dimensiones que consideramos fundamental tener en cuenta: cada tres años hasta el 2013 y se vuelven anuales hasta el 2017, último año disponible.

${ }^{3}$ Entendemos por renta familiar aquella que se genera por la agregación de las rentas personales totales de todos los miembros de una misma familia que cuentan con mayoría de edad y que perciben algún tipo de renta en el año considerado. En este estudio encontramos además la tipología de las rentas familiares y por lo tanto las diferentes tipologías de la procedencia de los ingresos en los hogares. Para más información ver:

https://www.eustat.eus/estadisticas/tema 395/opt 0/tipo 5/ ti renta-personal-y-familiar/temas.html\#el

${ }^{4}$ Es importante señalar que hay aspectos significativos que no se recogen en las estadísticas: hay personas que no declaran, hay personas que evaden capital y no se recoge información sobre el origen de las rentas y no sabiendo si los capitales provienen de una herencia o si fueron acumulados por las familias a lo largo de un periodo de su vida a partir de sus ingresos de trabajo. 
A. La distribución de la renta familiar por deciles ${ }^{5}$, lo que nos ha permitido crear diversos subgrupos de hogares en función de los ingresos.

B. La evolución de la renta familiar a lo largo del periodo en el que nos estamos centrando, es decir, de 2001 a 2017, así como los tipos de rentas que se ingresan en cada momento.

C. La renta disponible en los hogares, que nos proporciona una rica información sobre las posibilidades de ahorro y de gasto que han tenido y tienen las familias.

Más allá de estas dimensiones de análisis, las características sociodemográficas generales de la ciudad nos ayudan, además, a entender las rentas familiares. Bilbao, desde el punto de vista demográfico se caracteriza por tener una población envejecida: en 2019 el 18,1\% tenía más de 60 años, mientras que las personas menores de 25 años representaban al 20,5\% de la población. Una población que se concentra fundamentalmente en el área central de la ciudad, en barrios como Castaños, Indautxu y Abando, con un elevado porcentaje de hogares unipersonales $(30,9 \%)$ o bien formados por dos personas $(30,5 \%)$ (EUSTAT, 2018), situación que ha influido en la evolución del tamaño de los hogares, pasando a ser de un tamaño medio de 2,48 en 2010 a 2,33 en 2019 (INE, 2019). Este proceso se ha producido en paralelo a un descenso de población, perdiéndose en Bilbao en la última década 6.988 habitantes. Por otro lado, la crisis económica de 2008 ha golpeado en gran medida a los ingresos de los hogares, generando en muchos casos un elevado nivel de dependencia de las ayudas sociales, especialmente, de la Renta de Garantía de Ingresos (RGI): 13.146 hogares percibían dicha renta en Bilbao en 2019 (ARGAILAN, 2019). Esta dependencia ha afectado, sobre todo, a determinados barrios, como es el caso de Otxarkoga o San Francisco, donde el $12 \%$ de la población era perceptora de dicho ingreso en enero de 2020. Es en este contexto, precisamente, donde abordamos la renta familiar.

En cuanto a la distribución de la renta familiar por deciles, primera de las dimensiones a las que nos hemos referido anteriormente, nos ha permitido establecer diferentes subgrupos de hogares a partir de los ingresos. En 2017, en Bilbao, la forma de su distribución (FIG. 1) se asemeja a una "U" en la que los valores más altos se encuentran en los extremos. El $12,6 \%$ de la población tiene unos ingresos anuales inferiores a 9.870euros; se trata de hogares unipersonales, pensionistas, personas que viven solas o mujeres en paro con hijos a su cargo o personas que reciben la RGI. En 2017 esta renta era de 707,60 euros. En el otro extremo de la "U", el $11,1 \%$ de la población cuenta con una renta familiar que superar los 81.587 euros, es decir, se trata de ingresos ocho veces superiores a los del extremo inferior. Así mismo, es importante tener en cuenta que en Bilbao la renta media de los hogares era de 42.805 euros; por lo tanto, el $62 \%$ de las familias en Bilbao tienen unos ingresos familiares por debajo de la media.

\begin{tabular}{lr}
\hline Decil $1(<9,870 €)$ & 12,6 \\
\hline Decil $2(9.870-15.865 €)$ & 11,2 \\
\hline Decil 3 $(15.866-21.737 €)$ & 10,3 \\
\hline Decil $4(21.738-27.835 €)$ & 9,6 \\
\hline Decil $5(27.836-34.312 €)$ & 9,1 \\
\hline Decil $6(34.313-40.815 €)$ & 9,2 \\
\hline Decil $7(40.816-49.310 €)$ & 8,9 \\
\hline Decil $8(49.311-61.330 €)$ & 8,8 \\
\hline Decil $9(61.331-81.596 €)$ & 9,1 \\
\hline Decil 10 (>=81.597 $€)$ & 11,1 \\
\hline
\end{tabular}

FIG. 1/ Distribución por deciles de la renta familiar en Bilbao (\%) 2017.

Fuente: Estadística de la Renta Familiar (Eustat, 2019).

Esta distribución de la renta familiar, está en consonancia con su evolución. Aunque durante el periodo 2001 a 2017 , creció de forma significativa $(43,7 \%)$ en el conjunto de la ciudad, un análisis más detallado nos muestra la existencia de dos momentos: un periodo ascendente hasta 2009, para posteriormente disminuir paulatinamente (FIG. 2). Este cambio de tendencia, se puede explicar por dos factores fundamentalmente, por un lado, por el progresivo envejecimiento de la población, al que ya nos hemos referido más arriba, y, por otro lado, al impacto generado por la crisis económica, con un incremento del paro en 11.322 personas $(81,8 \%)$ en dicho periodo (EPA. 2007 y 2017).

Estos cambios que se han ido produciendo en la renta familiar están relacionados, a su vez, con la evolución que han seguido los diferentes tipos de rentas y que podemos explicar por medio de cuatro factores, como podemos ver en la FIG. 3:

\footnotetext{
5 Para más información sobre la definición del decil de la renta ver: https://www.eustat.eus/documentos/opt 0/tema 395/ elem 14478/definicion.html
} 


\begin{tabular}{lcccccccccccc}
\hline & 2001 & 2003 & 2006 & 2009 & 2011 & 2013 & 2014 & 2015 & 2016 & 2017 & Dif. & $\%$ \\
\hline $\begin{array}{l}\text { Renta } \\
\text { familiar }\end{array}$ & 29.730 & 32.463 & 39.679 & 43.119 & 41.920 & 40.951 & 40.806 & 41.535 & 42.370 & 42.805 & 13.017 & 43,7
\end{tabular}

FIG. 2/ Evolución de la renta familiar en Bilbao (€) 2001-2017.

Fuente: elaboración propia a partir de datos de EUSTAT.

\begin{tabular}{|c|c|c|c|c|c|c|c|c|c|c|}
\hline Tipos de rentas & 2001 & 2003 & 2006 & 2009 & 2011 & 2013 & 2014 & 2015 & 2016 & 2017 \\
\hline Renta total & 100 & 100 & 100 & 100 & 100 & 100 & 100 & 100 & 100 & 100 \\
\hline Renta del trabajo & 63,2 & 63,5 & 59,2 & 61,3 & 61,1 & 59,7 & 59,8 & 57,9 & 57,9 & 58,7 \\
\hline Renta capital mobiliario & 6,2 & 6,8 & 12,6 & 9,9 & 8,6 & 8,1 & 7,8 & 6,8 & 7,1 & 6,3 \\
\hline Renta capital inmobiliario & 1,7 & 1,6 & 1,7 & 1,8 & 2,1 & 2,0 & 1,9 & 2,2 & 2,3 & 2,4 \\
\hline Renta de actividades & 6,8 & 6,3 & 5,6 & 4,7 & 4,8 & 4,6 & 4,6 & 5,6 & 5,2 & 5,2 \\
\hline Transferencias & 21,9 & 21,3 & 20,6 & 22,0 & 23,2 & 25,6 & 25,6 & 27,2 & 27,3 & 27,2 \\
\hline
\end{tabular}

FIG. 3/ Distribución de los ingresos de la renta familiar en los hogares en Bilbao (\%) 2001-2017.

Fuente: elaboración propia a partir de datos de EUSTAT.

A. El primero de estos factores está condicionado por los salarios, es decir, por las rentas del trabajo. Entre 2001 y 2017 el salario ha perdido su relevancia como principal fuente de ingresos en las familias, pasando de representar el $63,2 \%$ de las rentas salariales al $59,7 \%$. Esto se ha debido también al protagonismo que han ido adquiriendo otras rentas en los hogares, como es el caso de las transferencias.

B. En segundo lugar, las rentas de transferencias, como hemos dicho, van adquiriendo una mayor importancia durante este periodo, pasando del $21,9 \%$ al $27,2 \%$. Las causas que justifican este incremento se deben, en gran medida, al progresivo envejecimiento de la población (pensiones) y a las ayudas sociales que reciben cada vez más familias debido a la situación de vulnerabilidad que atraviesan muchos hogares.

C. En tercer lugar, los ingresos provenientes de las rentas de capital inmobiliario (alquileres y venta de bienes inmuebles...) han adquirido paulatinamente un cierto protagonismo, del $1,7 \%$ al $2,4 \%$.

D. Y finalmente, los ingresos derivados de los ahorros financieros (renta de capital mobiliario)

\footnotetext{
${ }^{6}$ El interés legal del dinero en España estaba en el año 2002 al 4,25\%, pasando en el año 2017 al 3\%.

7 Bilbao tiene 40 barrios y 8 distritos. La metodología que se ha seguido ha sido la siguiente: se han clasificado los barrios basándonos en los niveles de ingresos de la renta familiar creando una serie de tipologías; de cada tipología se
}

han perdido su importancia, sobre todo a partir de 2006, debido en gran medida a la caída de los intereses bancarios y al acceso a un dinero más barato 6 .

Globalmente, se ha producido un importante incremento la renta familiar durante todo este periodo, pero se trata de un incremento muy desigual: en general, la renta familiar media en Bilbao ha pasado de 29.730 euros en 2001 a 42.805 euros en 2017 . Estas variaciones se han producido tanto en relación a los distintos tipos de rentas que componen los ingresos en los hogares, pero, sobre todo, por el incremento de la renta de transferencia.

\section{La dimensión espacial de la renta familiar en la ciudad y su estructura por barrios}

La capacidad económica de las familias está directamente ligada a la renta familiar. En el presente trabajo hemos analizado la distribución espacial de la misma por barrios. Teniendo en cuenta los diferentes niveles de ingresos familiares hemos podido describir cinco tipologías ${ }^{7}$, cinco "Bilbaos", a los que nos hemos referido y que hemos representado en la FIG. 4. 


\begin{tabular}{|c|c|c|c|c|c|c|c|c|}
\hline $\begin{array}{l}\text { Tipo de } \\
\text { barrio }\end{array}$ & $\begin{array}{l}\text { Renta } \\
\text { familiar } \\
\text { (euros) }\end{array}$ & Denominación del barrio & $\begin{array}{l}\text { Renta } \\
\text { media } \\
(2017)\end{array}$ & $\begin{array}{l}\text { Desviación } \\
\text { media }\end{array}$ & $\begin{array}{l}\text { Rango } \\
\text { (euros) }\end{array}$ & $\begin{array}{l}\text { Población } \\
\text { (2019) }\end{array}$ & $\begin{array}{l}\text { № de } \\
\text { barrios }\end{array}$ & $\begin{array}{l}\text { \% de } \\
\text { población } \\
\text { sobre el } \\
\text { total de } \\
\text { Bilbao }\end{array}$ \\
\hline $\begin{array}{l}1 . \\
\text { Rentas } \\
\text { altas }\end{array}$ & $\begin{array}{l}75.000 \\
- \\
60.000\end{array}$ & Abando, Indautxu & 73.540 & 0,09 & 185 & 51.507 & 2 & 14,5 \\
\hline $\begin{array}{l}2 . \\
\text { Rentas } \\
\text { medias- } \\
\text { altas }\end{array}$ & $\begin{array}{l}60.001 \\
- \\
50.000\end{array}$ & Castaños & 58.908 & - & 0 & 5.689 & 1 & 1,6 \\
\hline $\begin{array}{l}3 . \\
\text { Rentas } \\
\text { medias }\end{array}$ & $\begin{array}{l}50.001 \\
- \\
40.000\end{array}$ & $\begin{array}{l}\text { Ametzola, Basurtu, } \\
\text { Begoña, Casco Viejo } \\
\text { Bilbao, Ciudad Jardín, } \\
\text { Ibarrekolanda, Miribilla, } \\
\text { San Pedro de Deusto, } \\
\text { Txurdinaga }\end{array}$ & 46.376 & 1,88 & 6.368 & 94.935 & 10 & 26,8 \\
\hline $\begin{array}{l}4 . \\
\text { Rentas } \\
\text { Medias- } \\
\text { bajas }\end{array}$ & $\begin{array}{l}40.001 \\
- \\
30.000\end{array}$ & $\begin{array}{l}\text { Arangoiti, Atxuri, } \\
\text { Errekaldeberri, Iralabarri, } \\
\text { Iturralde, La Peña, } \\
\text { La Ribera, Larraskitu, } \\
\text { Masustegi-Monte } \\
\text { Caramelo, Matiko, } \\
\text { Olabeaga, San Adrián, } \\
\text { San Ignacio, Santutxu, } \\
\text { Solokoetxe, Uribarri, } \\
\text { Zorrotza, Zurbaran. }\end{array}$ & 34.298 & 3.15 & 9.216 & 154.413 & 18 & 43,6 \\
\hline $\begin{array}{l}5 . \\
\text { Rentas } \\
\text { bajas }\end{array}$ & $\begin{array}{l}30.001 \\
- \\
20.000\end{array}$ & $\begin{array}{l}\text { Altamira, Arabella, Bilbao la } \\
\text { Vieja, Bolueta, Otxarkoaga, } \\
\text { San Francisco, } \\
\text { Uretamendi, Zabala. }\end{array}$ & 26.457 & 2,5 & 7.598 & 47.261 & 9 & 13,3 \\
\hline \multicolumn{3}{|c|}{ Renta media familiar de los barrios } & $38.041,4$ & 8,6 & 51.332 & 353.805 & 40 & 100 \\
\hline \multicolumn{3}{|c|}{$\begin{array}{l}\text { Renta media familiar de las familias en } \\
\text { Bilbao }\end{array}$} & 42.805 & 11,7 & - & 353.805 & 40 & 100 \\
\hline
\end{tabular}

FIG. 4/ Distribución de los Barrios de Bilbao según los diferentes tipos de renta familiar (2017).

Fuente: elaboración propia basada en el EustaT (2001-2017).

Las tipologías que hemos realizado son las siguientes:

- Tipo 1. Barrios con renta alta. Se caracterizan por tener una renta familiar media de 73.7540 euros, renta que supone el 93,3\% superior a la media y presentando una desviación media 0,09. Este tipo está formado por dos barrios: Abando e Indautxu, en los que vive el $14,6 \%$ de la población de Bilbao.

- Tipo 2. Barrios con renta media-alta. La renta media familiar es de 58.908 euros, un $54,8 \%$ superior a la media. En este tipo de barrios con rentas medias-altas únicamente se incluye un barrio, Castaños, en el que vive el 1,6\% de la población de Bilbao.

- Tipo 3. Barrios con renta media. En este caso, la renta familiar media es de 43.376 euros, renta que supone el $21,9 \%$ superior a la media y con una desviación media de 1,88. Lo constituyen diez barrios: Ametzola, Basurtu, Begoña, Casco Viejo, Ciudad Jardín, Ibarrekolanda, Miribilla, San Pedro de Deusto y Txurdinaga, cuya población conjunta supone el $26,8 \%$ de la de Bilbao.

- Tipo 4. Barrios con renta media-baja. Se trata de barrios en los que la renta media familiar es de 34.298 euros, el 8,0\% inferior a la media de la ciudad, con una desviación media 3,19. Lo constituyen dieciocho barrios: Arangoiti, Atxuri, Errekaldeberri, Iralabarri, Iturralde, La Peña, La Ribera, Larraskitu, Masustegi-Monte Caramelo, Matiko, Olabeaga, San Adrián, San Ignacio, Santutxu, Solokoetxe, Uribarri, Zorrotza y Zurbaran, barrios en los que vive el $43,6 \%$ de la población de Bilbao. 
- Tipo 5. Barrios con renta baja, donde la renta media familiar es de 26.457 euros, el $27,5 \%$ inferior a la media de Bilbao, con una desviación media 3,24. Este tipo está formado por ocho barrios: Altamira, Arabella, Bilbao la Vieja, Bolueta, Otxarkoaga, San Francisco, Uretamendi y Zabala.

Hemos considerado importante poder trasladar estas cinco tipologías al espacio urbano y observar cómo su distribución espacial está relacionada con una lógica centro-periferia (FIG. 5). Como podemos ver en esta figura, los barrios que tienen mayor renta ocupan el área central de la ciudad; se trata de un espacio que experimentó una sustancial transformación urbana en la década de los noventa y dos mil, frente a una periferia ocupada por aquellos barrios con rentas medias-bajas y rentas bajas. Entre ambos extremos se distribuyen el resto de los barrios que configuran Bilbao.
Como es de suponer, las características de estos barrios son muy diferentes entre sí, tanto a nivel económico, social como estructural. De manera que, con la finalidad de profundizar en la descripción de los mismos, hemos tenido en cuenta nueve indicadores, agrupados en torno a cinco dimensiones de análisis: sociodemográfica, inmigración, cohesión social, nivel de estudios y tamaño del hogar ${ }^{8}$. La selección de los indicadores, así como su agrupación posterior, responde a la lógica que seguimos en este artículo, de intentar vincular dichos indicadores con el modelo de crecimiento dual de la ciudad.

En la FIG. 6, hemos reflejado las dimensiones a las que nos estamos refiriendo y, a su vez, los indicadores que hemos tenido en cuenta en cada una de estas dimensiones. En la primera de las dimensiones, la sociodemográfica, hemos tenido en cuenta la edad, la población mayor de 65 años, los mayores de 75 años y

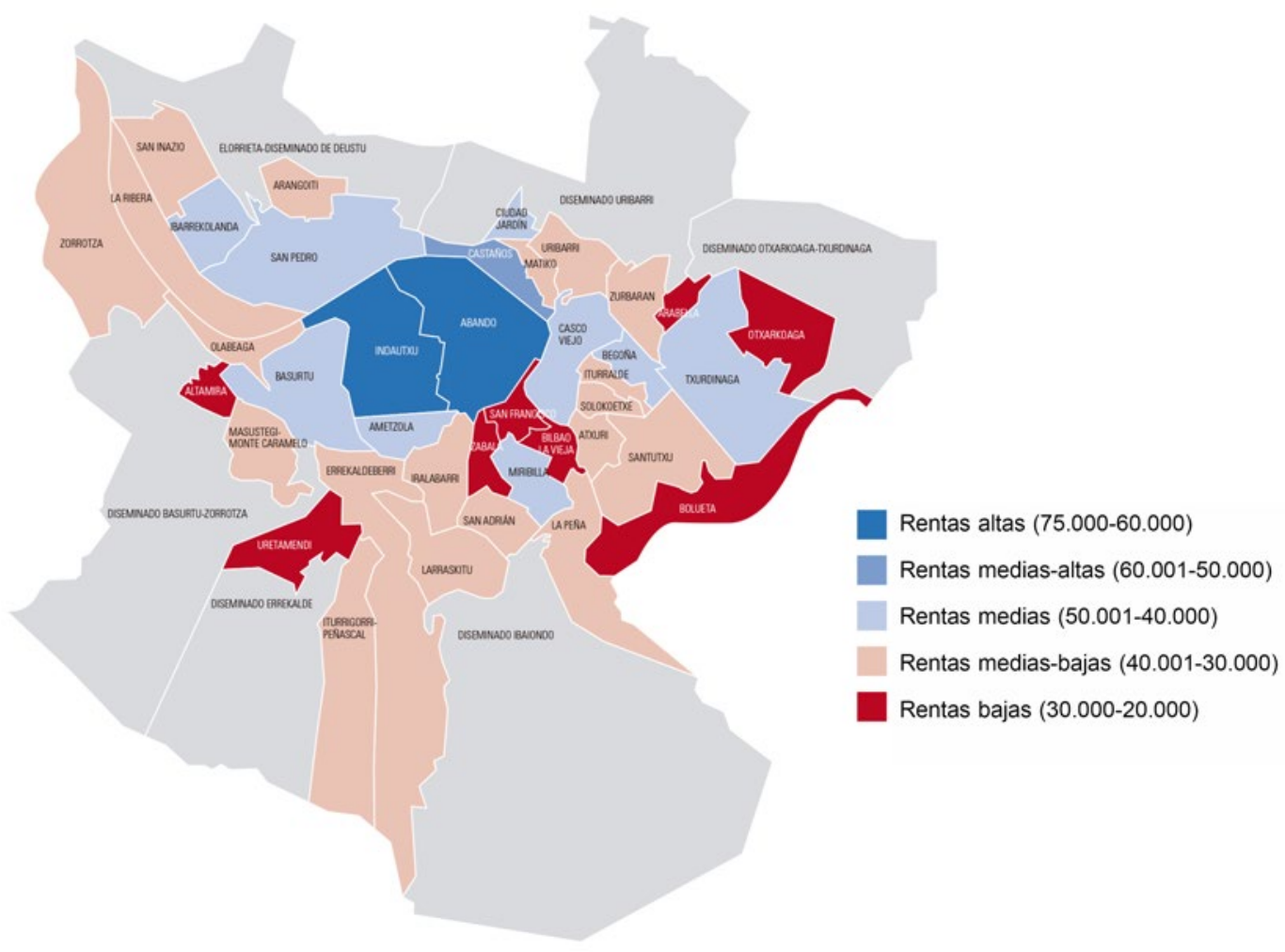

FIG. 5/ Distribución espacial de la renta familiar por barrios en Bilbao (2017).

Fuente: GoBIERNO VASco. Estadísticas de renta personal y familiar.

\footnotetext{
${ }^{8}$ La fuente de información empleada para la obtención de estos indicadores es el Observatorio de Bilbao, organismo dependiente del Ayuntamiento de Bilbao.
} 
los menores de 25 años, en 2019. El motivo por el que hemos tenido en cuenta estas edades es que las consideramos fundamentales por su relación con determinadas rentas como, por ejemplo, las pensiones (rentas de transferencia) y por las características demográficas de la población, vinculadas al envejecimiento de la población, entre otros motivos.

En cuanto a la dimensión vinculada a la inmigración en los barrios, hemos tenido en cuenta la presencia de población extranjera, ya que en algunos de estos barrios podemos hablar de una alta concentración de población procedente de otros países, y donde, además, diferentes indicadores les afectan en gran medida, como por ejemplo la recepción de $\mathrm{RGI}$, muy relacionada con la dimensión de la cohesión social ${ }^{9}$. La cohesión social es una de las dimensiones, al igual que la edad, más significativas en nuestro trabajo; para su análisis hemos recogido aquellos indicadores que están directamente vinculados con la precariedad, como la población en paro, y la población que por su situación económica es perceptora de la RGI. En este contexto, el impacto de la crisis ha generado una situación de insolvencia en muchas familias; esto nos ayuda a entender que aquellas rentas de transferencia vinculadas a las ayudas sociales, o al subsidio de desempleo, se constituyan en una fuente fundamental de ingresos en aquellos hogares que se encuentran en una situación de mayor vulnerabilidad. Los datos hacen referencia al año 2019.

Hemos considerado que el nivel de formación adquiere importancia en este análisis. Por ello hemos tenido en cuenta dos indicadores seleccionados por su capacidad discriminatoria: la población que tiene estudios superiores y la que carece de estudios o solo cuenta con estudios primarios. Los datos se refieren al año 2018.

Por último, nos hemos centrado en el tamaño del hogar. Bilbao se caracteriza por tener unos hogares pequeños, el promedio es de 2,3 personas por vivienda (2019). En los últimos años se ha incremento del número de personas que viven solas, hasta suponer un tercio de los hogares, lo que ha influido en que el tamaño de los hogares haya ido disminuyendo.

Atendiendo a esta selección y justificación de indicadores que hemos detallado, vamos a tratar de describir cada uno de barrios que componen la ciudad de Bilbao. Esto nos va a permitir conocer los aspectos más característicos de los cinco tipos de "Bilbaos" según la evolución del nivel de renta de las familias.

Entre los años 2001 a 2017 se da un incremento de la renta familiar en toda las tipologías, que oscila entre el $40 \%$ y el $57 \%{ }^{10}$. Este crecimiento se produce de forma muy desigual: las diferencias entre los barrios con rentas altas y los barrios con rentas bajas aumentan de forma considerable (FIG. 7), produciéndose de esta manera una fuerte polarización. Si la diferencia entre las rentas altas y las bajas era en 2001 de 28.325,8 euros, en 2017 ha sido de 47.083 euros; por lo tanto, este incremento diferencial ha sido de más de 18.000 euros. Por otro lado, estas diferencias de rentas no solo se aprecian en relación a los dos extremos de la distribución, sino

\begin{tabular}{llc} 
Dimensiones & Indicadores & Año \\
\hline Sociodemográficos & Población mayor de 65 años (\%) & 2019 \\
\hline Inmigración & Población mayor de75 años (\%) & 2019 \\
\hline Cohesión social & Población extranjera (\%) & 2019 \\
\hline Nivel de estudios & Población titular de la RGI (\%) & 25 años (\%) \\
\hline Tamaño del hogar & Población parada (\%) & 2018 \\
\hline
\end{tabular}

FIG. 6/ Indicadores seleccionados en los barrios.

\footnotetext{
${ }^{9}$ La población inmigrante, aunque no cuenten con permiso de residencia, tiene derecho a la cobertura económica procedente de la RGI. En este caso se les solicita una serie de requisitos, como llevar tres años empadronados en el País Vasco, constituir una unidad de convivencia, no disponer de recursos suficientes, tener más de 23 años, entre otros.
}

\footnotetext{
${ }^{10}$ En la tabla de la FIG. 7 únicamente presentamos los datos referidos a 2001 y 2017 . En la FIG.9 hemos incorporado la tabla completa con la información relativa a la renta familiar a todos los años del periodo según las tipologías de los barrios que hemos realizado. Así mismo, en la FIG. 10 hemos incorporado las rentas disponibles.
} 
también con respecto a la renta media: entre 2001 y 2017, la renta familiar de los dos barrios con rentas altas, Abando e Indautxu, crece el doble que la renta media de la ciudad de Bilbao.

Si bien la renta familiar nos proporciona la información de los ingresos que percibe un hogar, no lo hace sobre los recursos económicos con los que cuenta después del pago de los impuestos y la seguridad social. Es por ello que, con la finalidad de profundizar en un análisis más preciso de la renta familiar, debemos tener en cuenta la renta disponible, es decir, aquellos recursos económicos con los que cuenta una familia, tanto para gastar como para ahorrar ${ }^{11}$.

Un análisis de la renta familiar disponible de los hogares entre los años 2001 a 2017 nos muestra como esta ha aumentado en un $41,4 \%$. Pero es importante resaltar que, durante este periodo, la crisis dejó una importante huella: en 2017 la renta disponible era inferior a la del año 2009 en 2.842 euros (FIG. 8). Son los barrios con renta alta y media-alta los grandes beneficiarios de este ciclo económico, creciendo sus ingresos familiares entre 19.301 y 14.282 euros; en cambio los barrios con rentas media-bajas y bajas, crecen mucho menos, entre 10.215 y 8.143 euros.
Si se analizan los ocho años anteriores y posteriores a la crisis nos encontramos con importantes diferencias. En los momentos anteriores a la crisis, que coinciden con el proceso de transformación urbana de Bilbao (2001-2009), los dos barrios con las rentas más altas $(14,5 \%$ de la población de Bilbao) aumentaron sus ingresos en 22.143 euros de media, frente a los dieciocho barrios de renta media-baja $(43,6 \%$ de la población de Bilbao), que incrementaron sus ingresos en tan solo 8.899 euros.

Durante los años posteriores a la crisis, entre 2009 y 2017 , se da un descenso global en las rentas familiares disponibles. Son especialmente aquellos barrios con rentas altas y, en menor medida, aquellos con rentas medias los que experimentan un mayor descenso, 2.842 euros y 711,4 euros, respectivamente. Los barrios con rentas bajas apenas sufren variación entre estos años: su renta se reduce en 155 euros. Una de las razones de esta estabilidad hay que buscarla principalmente en el aumento de las transferencias vía ayudas sociales, especialmente de la $R G I$, que se da en dicho periodo. Si en el año 2009 suponían el $29,3 \%$ del ingreso familiar, en el año 2017 había ascendido hasta el 34,3\%.

\begin{tabular}{llllll}
\hline Nivel de renta $(€)$ & Tipo & $\mathbf{2 0 0 1}$ & $\mathbf{2 0 1 7}$ & \multicolumn{1}{c}{ Dif. } & $\%$ \\
\hline Bilbao & - & $\mathbf{2 9 . 7 3 0}$ & $\mathbf{4 2 . 8 0 5}$ & $\mathbf{1 3 . 0 1 7}$ & $\mathbf{4 3 , 7}$ \\
\hline $75.000-60.000$ & 1. Rentas altas & $46.639,5$ & 73.540 & $26.900,5$ & 57,6 \\
\hline $60.001-50.000$ & 2. Rentas medias-altas & 39.882 & 58.908 & 19.026 & 47,7 \\
\hline $50.001-40.000$ & 3. Rentas medias & $32.944,7$ & 46.376 & $13.431,3$ & 40,7 \\
\hline $40.001-30.000$ & 4. Rentas medias-bajas & $24.082,9$ & $34.298,1$ & $10.215,2$ & 42,4 \\
\hline $30.000-20.000$ & 5. Rentas bajas & $18.313,7$ & 26.457 & $8.143,3$ & 44,4 \\
\hline
\end{tabular}

FIG. 7 / Evolución de las rentas familiares por tipo de barrio (2001-2017).

Fuente: EustAT. Elaboración propia (valores medios).

\begin{tabular}{llccccc}
\hline Nivel de renta $(€)$ & Tipo & 2001 & 2009 & 2017 & Dif. & $\%$ \\
\hline Bilbao & - & 24.999 & 36.383 & 35.349 & 10.350 & 41,4 \\
\hline $75.000-60.000$ & 1. Rentas altas & $37.120,5$ & 59.264 & 56.422 & 19.301 & 51,9 \\
\hline $60.001-50.000$ & 2. Rentas medias-altas & 32.249 & 46.987 & 46.531 & 14.282 & 44,2 \\
\hline $50.001-40.000$ & 3. Rentas medias & $27.478,5$ & $38.976,4$ & 38.265 & $10.786,5$ & 39,2 \\
\hline $40.001-30.000$ & 4. Rentas medias-bajas & 20.908 & $29.807,6$ & 29.417 & 8.509 & 40,6 \\
\hline $30.000-20.000$ & 5. Rentas bajas & $16.309,5$ & $23.553,1$ & 23.398 & $7.088,5$ & 43,4
\end{tabular}

FIG. 8/ Evolución de la renta familiar disponible en Bilbao según las tipologías de barrios (2001-2017).

\footnotetext{
11 La renta disponible resulta de descontar a la renta personal total los gastos de Seguridad Social y la cuota líquida o las retenciones a cuenta.
} 


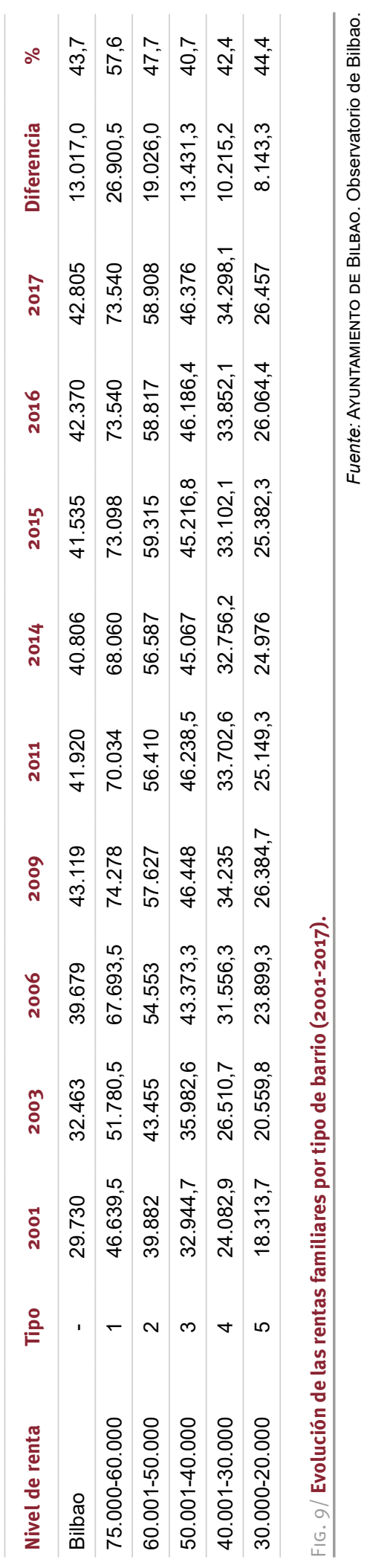

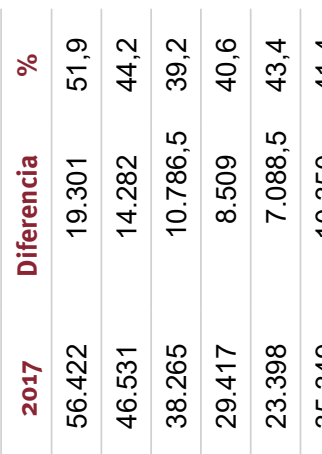

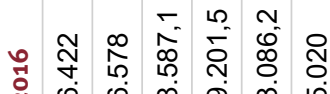

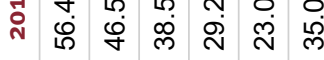

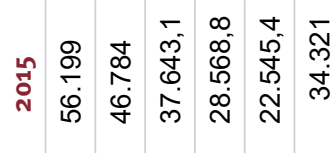

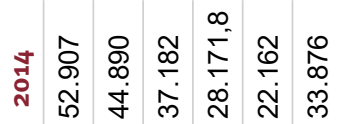

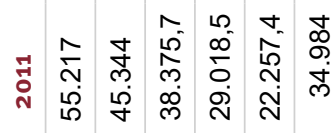

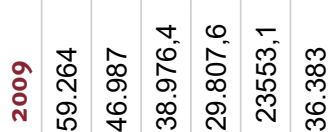

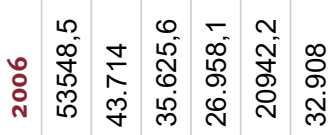

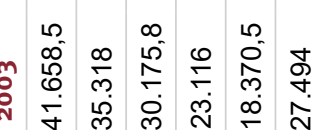

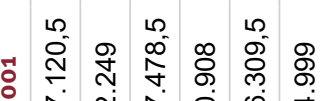

กे

$\stackrel{\circ}{\stackrel{2}{2}}-2 m+\infty$

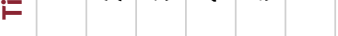

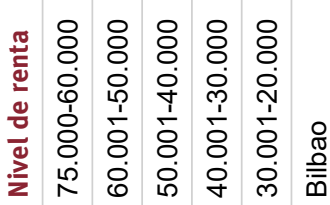

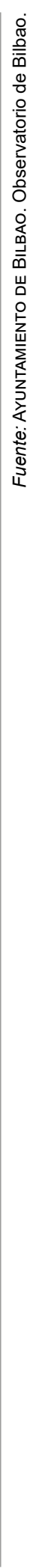


Detengámonos en las características principales de estos cinco tipos de barrios que configuran la estructura de Bilbao.

\section{Tipología 1 y 2: barrios con renta familiar alta y media-alta}

Como ya se ha indicado, esta tipología la constituyen los barrios de Indautxu y Abando, localizados en el centro de la ciudad, siendo el espacio donde se desarrollaron los principales proyectos de la transformación urbana de Bilbao: el Museo Guggenheim, las Torres de Isozaki o el Puente de Calatrava, entre otras actuaciones urbanísticas.

Son los barrios con la mayor renta de la ciudad, 73.540 euros en 2017 , el $41,7 \%$ por encima de la media de la ciudad. Tienen un alto porcentaje de población con estudios superiores, más del $42 \%$, muy por encima de la media de Bilbao, que es del $22,7 \%$. La tasa de paro está por debajo de la media, rondando el $9 \%$, con baja presencia de población extranjera, entre un 6,5\% y un $4,8 \%$ (2019).

Su principal fuente de ingresos procede de las rentas de trabajo, es decir, del salario, siendo esta la fuente principal del ingreso familiar. Durante el periodo analizado se produce un cambio importante: a partir del 2006 los ingresos procedentes de los ahorros financieros (intereses de cuentas, dividendos de acciones...) caen de forma significativa, debido al abaratamiento del coste de dinero, la pérdida de intereses, especialmente a plazo fijo, y a la caída de la bolsa ${ }^{12}$.

En contraposición, los ingresos procedentes del cobro de alquileres y de la venta de viviendas o del alquiler de parcelas de garaje, es decir, los procedentes del capital inmobiliario, crecieron de forma constante a pesar de la crisis inmobiliaria iniciada en el año 2008. Son ingresos generados por rentas derivadas de las propiedades urbanas, llegando a ser un $4,1 \%$ de sus ingresos (2017). La causa hay que buscarla en los incrementos de los alquileres, por la expansión de los pisos turísticos a través de plataformas como Airbnb ${ }^{13}$, Homeaway, Booking.com, y por las modificaciones derivadas de la Ley de Arrendamientos Urbanos (2013). Estas modificaciones favorecieron a los propietarios: se acortaron de cinco a tres años los plazos para renovar los contratos de alquiler y les da la posibilidad de recuperar el piso ${ }^{14}$.

Las pensiones (transferencias) juegan un papel importante dentro de los ingresos familiares, llegando a suponer el $19,1 \%$ en 2017 . Esto es debido al alto nivel de envejecimiento de la población: en el año 2019, en el barrio de Indautxu, el $27,8 \%$ de la población tenía más de 65 años (un $15 \%$ más de 75 años), y en Abando un $25 \%$ (FIG. 11).

Tanto la renta de capital mobiliario como la de capital inmobiliario son rentas pasivas, que no vienen derivados de una actividad productiva, sino que son el resultado de las plusvalías derivadas por los intereses generados por los ahorros financieros (bienes de rentas de capital mobiliario) o por el cobro de alquileres o por el beneficio de la venta de bienes urbanos, son, en este sentido, rentas especulativas. Su relevancia en la tipología 1 (renta alta) es significativa: constituyen el $17,1 \%$ del ingreso familiar, mientras que en el conjunto de Bilbao es del $8,7 \%$ (2017).

En el caso del barrio de Castaños, único barrio en el tipo de renta media-alta, se encuentra localizado en el centro de la ciudad y representa el $1,6 \%$ de la población total. Está formado por viejas clases medias-altas y su nivel de envejecimiento es el más alto de la ciudad; el $36,7 \%$ de la población tiene más de 65 años y el $14,8 \%$ más de 75 años. La renta media era de 58.908 euros en 2107, un $37,2 \%$ por encima de la media de la ciudad; dichos ingresos provienen fundamentalmente de los salarios y de las pensiones $(24,1 \%)$ y en menor medida vinculados a los beneficios que dan los ahorros bancarios y capital mobiliario $(7,8 \%)$.

\footnotetext{
12 En noviembre del año 2017, el IBEX llegó a los 16.040 puntos de cotización, diez años después en julio el año 2007, estaba en 10.702 puntos. Bolsa de Madrid serie histórica.

${ }^{13}$ En el año 2017 solo la plataforma Airbnb ofertaba en Bilbao 1.404 pisos en alquiler.

14 El propietario puede recuperar la casa simplemente avisándole con dos meses de antelación y transcurrido un año
}

del contrato siempre que manifiesta una necesidad para sí mismo, para familiares en primer grado o conyugues en caso de separación. Para más información consultar el Real Decreto-ley $7 / 2019$, de 1 de marzo, de medidas urgentes en materia de vivienda y alquiler (BOE 55, 5 de marzo), https://www.boe.es/eli/es/rdl/2019/03/01/7 


\section{Tipología 3: barrios con renta} familiar media

Esta tipología está formada por los diez barrios a los que ya nos hemos referido y que constituyen el $26,8 \%$ de la población de Bilbao, situados geográficamente en el área central de la ciudad. Estos barrios están vinculados a las diversas fases de expansión residencial de la ciudad. Lo componen tres tipos de barrios según sus características que debemos tener en cuenta:

A. Barrios creados en la década de los setenta y ochenta, como es el caso de Ibarekolanda o Txurdinaga.

B. Los barrios de nueva creación como Amezola (1995) o Miribilla (1998).

C. Y por último, aquellos barrios que tuvieron fuertes crecimientos del parque de vivienda, situación derivada de la transformación urbana, como el conjunto de las Torres de Roger en Basurto ${ }^{15}$. Son barrios que presentan una tasa de paro baja, por debajo de la media (FIG. 11).

La renta media de estos barrios es de 46.376 euros, lo que supone el $8,3 \%$ por encima de la media de Bilbao Un análisis de la evolución los hogares muestra un periodo de transición que se manifiesta en la pérdida de protagonismo de los salarios como fuente de ingresos procedentes de la renta de trabajo, que pasa del $68,5 \%$ en el año 2001 al $62,5 \%$ en 2017; en cambio las pensiones, es decir, las transferencias, se incrementan al $18,7 \%$ en 2001 y al $25,8 \%$ en 2017. A pesar de esta evolución, es la tipología en la que el salario constituye la mayor fuente de ingresos.

\section{Tipologías 4 y 5: barrios con renta familiar media-baja y baja}

La tipología 4 la forman, como ya hemos dicho, dieciocho barrios localizados en la periferia de la ciudad, representando el $43,6 \%$ de la población de la ciudad. Se trata de la tipología que, desde nuestro punto de vista, es la más importante. Presenta unas características sociodemográficas muy diferentes internamente: una población envejecida en algunos barrios, como Zurbaran, Uribarri, Santutxu y Arangoiti, con una población mayor de 64 años por encima de la media alcanzando el 20,5\%; por el contrario, encontramos barrios como Arangoiti, Atxuri, Rekaldeberri, Iralabarri, Masustegui, San Adrián y San Ignacio, que tienen una población menor de 25 años superior a la media $(20,5 \%)$. Además, encontramos en estos barrios un bajo nivel de formación, exceptuando Santutxu y La Ribera, que están por encima de la media $(31,8 \%)$ (FIG. 11).

En cuanto a la renta media de estos barrios, en 2017 era de $34.298,1$ euros, un $19,8 \%$ por debajo de la media de la ciudad. Destacan por la dependencia que en ellos tienen los hogares de las rentas de transferencias, constituyendo un tercio de sus ingresos (FIG. 12). En diecisiete años, estas rentas de transferencias han pasado de representar el $23,8 \%$ al $30,4 \%$ de los ingresos de estos barrios, aumento que estaría relacionado principalmente con las ayudas sociales o el cobro de subsidios por desempleo o la RGI. De los dieciocho barrios que forman esta tipología, catorce tienen unas tasas de paro superior a la media, $14,5 \%$ en 2019 , Ilegando incluso al 20,9\% en el barrio de Arangoiti. Se da, por otro lado, una importante concentración de población extranjera, especialmente en Iralabarri $(13,3 \%)$, Errekaldeberri $(11,2 \%)$ e Iturralde $(10,5 \%)$, superando en todos los casos la media de la población extranjera en Bilbao, que era de 9,5\% en 2019.

Estos barrios se caracterizan, además, por un bajo nivel de instrucción: de los dieciocho barrios solo cuatro, Solokoetxe, San Ignacio, La Ribera e Iturralde, están ligeramente por encima por debajo de la media de Bilbao en lo que se refiere al porcentaje de personas sin estudios o con estudios primarios; el resto de barrios presentan datos peores que la media y en algunos de ellos, como Arangoiti, La Peña, Larraskitu o Zorrotza, el porcentaje de personas analfabetas o solo con estudios primarios supera incluso el $40 \%$.

La tipología 5, aquellos barrios con los niveles de renta más bajos, presenta características propias, representa el $13,3 \%$ de la población y, por sus particularidades, se podría definir como la situación extrema en términos de desigualdad y exclusión social. Formada por nueve barrios, que aglutinan a la población más joven de la ciudad, seis de ellos presentan una tasa población inferior a 25 años superando a la media $(20,5 \%)$, excepto en el caso del barrio de Altamira, que se caracteriza por tener una población mayor de 65 años superior a la media $(23,9 \%)$ en 2019.

\footnotetext{
${ }^{15}$ Un proyecto de 612 viviendas de VPO y 440 viviendas libres.
} 


\begin{tabular}{|c|c|c|c|c|c|c|c|c|c|}
\hline & \multicolumn{3}{|c|}{ Sociodemográficos } & \multirow{2}{*}{$\begin{array}{l}\text { Inmigración } \\
\text { \% pobl. } \\
\text { extranjera } \\
\text { (2019) }\end{array}$} & \multirow{2}{*}{$\begin{array}{c}\text { Cohesión } \\
\text { social } \\
\% \text { de } \\
\text { pobl. } \\
\text { titular de } \\
\text { RGI } \\
(2019)\end{array}$} & \multirow{2}{*}{$\begin{array}{c}\text { Mercado } \\
\text { de trabajo } \\
\% \\
\% \\
\text { parados } \\
(2018)\end{array}$} & \multicolumn{2}{|c|}{ Nivel de estudios } & \multirow{2}{*}{$\begin{array}{c}\text { Tamaño } \\
\text { del hogar } \\
\text { Habs. } \\
\text { /vivienda } \\
\text { (2015) }\end{array}$} \\
\hline & $\begin{array}{c}\% 75 \\
\text { años } \\
(2019)\end{array}$ & $\begin{array}{c}\%+ \\
64 \\
\text { años } \\
(2019)\end{array}$ & $\begin{array}{c}\%-25 \\
\text { años } \\
(2019)\end{array}$ & & & & $\begin{array}{c}\text { \% estudios } \\
\text { superiores } \\
(2018)\end{array}$ & $\begin{array}{c}\% \\
\text { analfabetos } \\
\text { e. primarios } \\
(2018)\end{array}$ & \\
\hline \multicolumn{10}{|l|}{ Tipología 1} \\
\hline Abando & 12,8 & 25,0 & 21.1 & 6,5 & 1,5 & 9,4 & 43,3 & 14,8 & 2,4 \\
\hline Indautxu & 15,3 & 27,8 & 20,7 & 4,8 & 0,9 & 9 & 42,4 & 14,4 & 2,4 \\
\hline \multicolumn{10}{|l|}{ Tipología 2} \\
\hline Castaños & 14,8 & 36,7 & 19,2 & 5 & 1,5 & 8,7 & 18,4 & 8,6 & 2,4 \\
\hline \multicolumn{10}{|l|}{ Tipología 3} \\
\hline Ametzola & 14 & 31,5 & 20 & 13,2 & 3,0 & 12,7 & 27,7 & 25,9 & 2,4 \\
\hline Basurtu & 14 & 25,9 & 17,4 & 6,1 & 1,9 & 10,3 & 29,4 & 23,8 & 2,3 \\
\hline Begoña & 15,8 & 34,6 & 16,4 & 5,6 & 1,8 & 11,7 & 23,5 & 27,9 & 2,4 \\
\hline Casco Viejo & 7,9 & 16,1 & 20,3 & 9,8 & 4,4 & 11,8 & 36,9 & 19,9 & 2,2 \\
\hline Ciudad Jardín & 10,4 & 20,1 & 21,9 & 4 & 3,3 & 14,5 & 28 & 27 & 2,6 \\
\hline Ibarrekolanda & 14,5 & 28,9 & 17,7 & 6,8 & 2,0 & 12,9 & 23,3 & 29,5 & 2,4 \\
\hline Miribilla & 2,7 & 6,4 & 31,3 & 3,2 & 1,1 & 7,4 & 28,3 & 20,7 & 2,6 \\
\hline $\begin{array}{l}\text { S. Pedro de } \\
\text { Deusto }\end{array}$ & 14,2 & 28 & 19,1 & 6,5 & 1,7 & 10,5 & 29,8 & 21,7 & 2,4 \\
\hline Txurdinaga & 15,7 & 22,7 & 20,5 & 2,6 & 2,9 & 13,2 & 17,8 & 34,7 & 2,6 \\
\hline \multicolumn{10}{|l|}{ Tipología 4} \\
\hline Arangoiti & 12,7 & 29,6 & 21 & 9,7 & 3,9 & 20,9 & 10,5 & 45,3 & 2,4 \\
\hline Atxuri & 12,3 & 20,4 & 21,3 & 10,2 & 6,6 & 16,8 & 18,2 & 37 & - \\
\hline Errekaldeberri & 12.7 & 21.9 & 21,3 & 11,2 & 4,8 & 16,4 & 14,1 & 41,6 & - \\
\hline Iralabarri & 12,4 & 21,8 & 21,1 & 13,3 & 5,0 & 15,6 & 20,5 & 33,1 & 2 \\
\hline Iturralde & 10,9 & 21,4 & 19,7 & 10,5 & 4,2 & 14,9 & 22,5 & 26,8 & 2,4 \\
\hline La Peña & 10,3 & 22,1 & 21,8 & 8,5 & 4,1 & 16,9 & 10,2 & 45,3 & 2,3 \\
\hline La Ribera & 8,6 & 21 & 19,6 & 8,9 & 3,0 & 12,3 & 24,5 & 30 & 2,5 \\
\hline Larraskitu & 12,9 & 19,9 & 22,3 & 10,5 & 4,0 & 14,7 & 11,8 & 41,2 & 2,3 \\
\hline $\begin{array}{l}\text { Masustegi - } \\
\text { M.C. }\end{array}$ & 8,1 & 16,1 & 23,5 & 6,2 & 2,5 & 12,5 & 17,6 & 36,7 & - \\
\hline Matiko & 13,6 & 32,7 & 19,7 & 8,5 & 5,2 & 12,8 & 21,4 & 31,7 & 2,2 \\
\hline Olabeaga & 9,6 & 17,8 & 17,3 & 7,5 & 5,7 & 18,3 & 17 & 37,1 & 2,1 \\
\hline San Adrián & 10,5 & 20,9 & 22,4 & 8,5 & 3,7 & 16,8 & 16,2 & 35,5 & 2,5 \\
\hline San Ignacio & 14,3 & 23,6 & 21,7 & 7,4 & 1,9 & 12,6 & 18,9 & 31,6 & 2,4 \\
\hline Santutxu & 16,7 & 29,3 & 18,2 & 7,8 & 4,7 & 16,7 & 14 & 40,8 & 2,3 \\
\hline Solokoetxe & 12,4 & 23,5 & 19,7 & 10,4 & 4,4 & 16 & 21,5 & 29,7 & 2,3 \\
\hline Uribarri & 16 & 26,6 & 18,2 & 10,3 & 5,0 & 15,3 & 15,3 & 35,5 & - \\
\hline Zorrotza & 11,9 & 23,7 & 20,5 & 8,2 & 3,8 & 16,6 & 9,5 & 44,3 & 2,4 \\
\hline Zurbaran & 17,2 & 31,7 & 18,2 & 7,7 & 4,1 & 14,2 & 17,1 & 37,6 & 2,3 \\
\hline \multicolumn{10}{|l|}{ Tipología 5} \\
\hline Altamira & 16,5 & 25,5 & 19,8 & 10,7 & 4,7 & 17,7 & 8,1 & 50,4 & 2,3 \\
\hline Arabella & 11,8 & 19,5 & 23,9 & 14 & 7,6 & 18,4 & 11,4 & 39,9 & 2,3 \\
\hline Bilbao la Vieja & 5,9 & 16,2 & 23,8 & 14 & 8,2 & 21,2 & 18,4 & 35,1 & 2,2 \\
\hline Bolueta & 10,2 & 22,9 & 19,9 & 9,9 & 5,2 & 18,7 & 11,7 & 44,3 & 2,4 \\
\hline Iturrigorri-P. & 9,2 & 17,2 & 25,1 & 15,4 & 9,8 & 30,1 & 4,3 & 55,8 & 2,4 \\
\hline Otxarkoaga & 12,1 & 19,7 & 22,9 & 8,1 & 12,0 & 30,7 & 5,5 & 54 & 2,3 \\
\hline San Francisco & 6,5 & 13,5 & 19,3 & 27,5 & 12,0 & 28,4 & 18,7 & 39,3 & 2,4 \\
\hline Zabala & 11,9 & 20 & 22,1 & 20,9 & 8,0 & 24,1 & 14,4 & 40 & 2,4 \\
\hline Uretamendi & 12,7 & 22,4 & 20,1 & 12 & 8,6 & 23,8 & 5,3 & 56,9 & 2,3 \\
\hline BILBAO & 12,9 & 23,9 & 20,5 & 8,5 & - & 14,5 & 22,7 & 31,8 & 2,4 \\
\hline
\end{tabular}

FIG. 11/ Indicadores de los barrios por su tipología de Bilbao.

Fuente: AyuntAMIENTO DE BILBAo. Observatorio de Bilbao. 
En este tipo el nivel de instrucción es muy bajo, el número de personas sin estudios o con estudios primarios en algunos barrios supera el $50 \%$ como en el caso de Altamira, Iturriogorri-Peñascal, Uretamendi y Otxarkoaga (2019). Las tasas de paro son también muy altas en todos los barrios especialmente en los casos de Otxarkoaga $(30,7 \%)$ o Iturrigorri-Peñascal $(30,1 \%)$ duplican la media de Bilbao (14,5\%). La población extranjera es muy representativa, especialmente en el barrio de San Francisco, con el $27,5 \%$, y el caso de Zabala, donde llega al 20,9\%.

La renta familiar media era en 2017 de 26.447 euros, un 30,4\% por debajo de la renta media de Bilbao. La situación más extrema la encontramos en el barrio de Iturrigorri-Peñascal, con una renta familiar de 22.300 euros. Más de un tercio de los ingresos familiares, el 34,4\% están vinculados a la renta de transferencia a través

\begin{tabular}{|c|c|c|c|c|c|c|c|c|c|c|}
\hline Renta & Tipo de renta & 2001 & 2003 & 2006 & 2009 & 2011 & 2014 & 2015 & 2016 & 2017 \\
\hline \multirow{6}{*}{$\begin{array}{l}\text { Tipo } 1 \\
75.000- \\
60.000\end{array}$} & Renta total & 100 & 100 & 100 & 100 & 100 & 100 & 100 & 100 & 100 \\
\hline & Renta del trabajo & 54,7 & 55,4 & 49,5 & 56,4 & 55,0 & 54,7 & 52,6 & 52,3 & 54,9 \\
\hline & Renta capital mobiliario & 12,4 & 13,8 & 23,7 & 17,7 & 16,3 & 14,7 & 17,5 & 15,5 & 13,0 \\
\hline & Renta capital inmobiliario & 3,3 & 3,2 & 3,0 & 3,2 & 3,8 & 3,7 & 3,7 & 3,9 & 4,1 \\
\hline & Renta de actividades & 10,6 & 10,0 & 8,4 & 7,0 & 7,7 & 7,8 & 9,9 & 8,5 & 8,6 \\
\hline & Transferencias & 18,7 & 17,4 & 15,2 & 15,5 & 17,0 & 18,9 & 18,8 & 18,8 & 19,1 \\
\hline \multirow{6}{*}{$\begin{array}{l}\text { Tipo } 2 \\
60.00- \\
50.001\end{array}$} & Renta total & 100 & 100 & 100 & 100 & 100 & 100 & 100 & 100 & 100 \\
\hline & Renta del trabajo & 67,1 & 66,5 & 59,2 & 60,4 & 61,5 & 58,6 & 57,0 & 58,7 & 57,9 \\
\hline & Renta capital mobiliario & 6,3 & 7,0 & 16,4 & 12,7 & 9,4 & 11,1 & 10,5 & 7,5 & 7,8 \\
\hline & Renta capital inmobiliario & 2,1 & 2,1 & 2,1 & 2,5 & 2,7 & 2,5 & 2,7 & 3,1 & 3,1 \\
\hline & Renta de actividades & 6,9 & 6,9 & 5,3 & 5,6 & 6,0 & 5,3 & 6,8 & 6,8 & 6,8 \\
\hline & Renta de transferencia & 17,5 & 15,5 & 16,8 & 18,6 & 20,2 & 22,2 & 22,8 & 23,6 & 24,1 \\
\hline \multirow{6}{*}{$\begin{array}{l}\text { Tipo } 3 \\
50.000- \\
40.001\end{array}$} & Renta total & 100 & 100 & 100 & 100 & 100 & 100 & 100 & 100 & 100 \\
\hline & Renta del trabajo & 68,5 & 68,6 & 63,6 & 66,4 & 65,9 & 63,5 & 62,8 & 62,7 & 62,5 \\
\hline & Renta capital mobiliario & 4,9 & 5,2 & 10,0 & 7,9 & 7,1 & 7,2 & 5,7 & 5,3 & 5,4 \\
\hline & Renta capital inmobiliario & 1,6 & 1,6 & 1,6 & 1,7 & 1,9 & 1,7 & 2,0 & 2,1 & 2,3 \\
\hline & Renta de actividades & 6,1 & 5,7 & 5,0 & 4,4 & 4,0 & 3,7 & 4,0 & 4,0 & 4,1 \\
\hline & Transferencias & 18,7 & 18,7 & 19,9 & 19,5 & 20,9 & 23,6 & 25,2 & 25,9 & 25,8 \\
\hline \multirow{6}{*}{$\begin{array}{l}\text { Tipo } 2 \\
40.000 \text { - } \\
30.001\end{array}$} & Renta total & 100 & 100 & 100 & 100 & 100 & 100 & 100 & 100 & 100 \\
\hline & Renta del trabajo & 65,8 & 65,7 & 63,4 & 63,8 & 63,4 & 62,0 & 60,0 & 60,5 & 60,6 \\
\hline & Renta capital mobiliario & 3,7 & 4,2 & 7,4 & 6,3 & 5,2 & 4,5 & 3,9 & 3,3 & 3,3 \\
\hline & Renta capital inmobiliario & 0,9 & 0,9 & 1,0 & 1,1 & 1,2 & 1,1 & 1,3 & 1,4 & 1,5 \\
\hline & Renta de actividades & 5,3 & 5,0 & 4,6 & 3,9 & 3,8 & 3,5 & 3,9 & 4,0 & 3,9 \\
\hline & Transferencia & 23,8 & 23,3 & 23,0 & 25,5 & 26,0 & 28,4 & 30,6 & 30,6 & 30,4 \\
\hline \multirow{6}{*}{$\begin{array}{l}\text { Tipo } 1 \\
30.000- \\
20.001\end{array}$} & Renta total & 100 & 100 & 100 & 100 & 100 & 100 & 100 & 100 & 100 \\
\hline & Renta del trabajo & 62,7 & 63,6 & 62,2 & 62,6 & 63,1 & 61,7 & 56,0 & 57 & 59,9 \\
\hline & Renta capital mobiliario & 3,3 & 3,2 & 5,2 & 4,2 & 3,2 & 2,7 & 2,2 & 1,9 & 1,8 \\
\hline & Renta capital inmobiliario & 0,5 & 0,5 & 0,6 & 0,6 & 0,8 & 0,8 & 0,9 & 0,9 & 1,1 \\
\hline & Renta de actividades & 5,5 & 5,0 & 4,7 & 4,0 & 3,9 & 3,5 & 4,1 & 4,1 & 4,5 \\
\hline & Transferencias & 29 & 28,3 & 27,5 & 29,3 & 29,4 & 30,8 & 36,5 & 35,8 & 34,4 \\
\hline
\end{tabular}

FIG. 12/ Distribución de los ingresos de la renta familiar según la tipología de barrio 2001-2017 (\%). 
de ayudas sociales y de la RGI. En 2019, el 12\% de la población de los barrios de Otxarkoaga y San Francisco eran perceptores de dicha ayuda, mientras que, en barrios como Zabala, Uretamendi, Iturrigorri-Peñascal y Bilbao La Vieja, estaban entre el 8 y el $10 \%$ de su población (ARGAILAN, 2019).

Como podemos comprobar, por medio del análisis de las rentas familiares es evidente que la distancia en términos de renta familiar entre aquellos barrios con renta alta, que agrupa al $14,5 \%$ de los habitantes de Bilbao y los de renta media baja y baja, que suponen un $57 \%$ de la población, ha aumentado de manera significativa y ha propiciado un modelo de desarrollo urbano dual.

\section{Las políticas de vivienda}

Las políticas de vivienda que ha desarrollado el Gobierno Vasco, ha tenido importantes consecuencias en la ciudad; de hecho, es uno de los factores que ha contribuido a este modelo de crecimiento dual entre 2001 y 2017 . Uno de los efectos no deseados, o no previstos ${ }^{16}$, de dichas políticas es el reforzamiento de la dicotomía urbana, debida a la orientación de sus políticas de viviendas a la creación de una base social de propietarios por medio de la promoción de las Viviendas de Protección Oficial (VPO), más que a tratar de resolver las necesidades habitacionales de aquellos colectivos (jóvenes, personas divorciadas, inmigrantes...) con mayor necesidad de una vivienda. El alquiler para aquellos grupos que no cuentan con recursos económicos suficientes para poder acceder a una vivienda digna, un problema agudizado sobre todo a partir de la crisis del 2008, no quedará suficientemente recogido en los sucesivos Planes Directores de Vivienda ${ }^{17}$. Hay que esperar a la Ley $3 / 2015$ de Vivienda para que el panorama cambie profundamente, y esto se produce por medio del reconocimiento subjetivo del derecho a la vivienda y a una ocupación estable para quien no tiene acceso a ella y por la apuesta

\footnotetext{
16 Son resultado de acciones no previstas o no intencionadas, según lo popularizo el sociólogo R. Karl MERTON (2002). 17 Gobierno Vasco: Planes de Vivienda 2002-2005, 20062009, 2010-2012, 2013-2016 y 2018-2020.

${ }_{18}$ La ley apuesta por el régimen de alquiler, de modo que los recursos de las políticas de vivienda (exceptuando los dedicados a rehabilitación urbana) deberán estar destinados a políticas de alquiler. Hasta un $80 \%$ de los recursos en materia de vivienda se destinarán a políticas de alquiler (art. 7.4. de la ley).

${ }^{19}$ La ley $17 / 1994$ también conocida como Ley Maturana permitió la creación de importantes reservas de suelo para la
}

por el alquiler como eje central de las políticas de vivienda ${ }^{18}$. En este contexto, la repercusión que tienen los diversos planes de vivienda en el diseño de la política habitacional que se ha desarrollado en Bilbao es importante.

Algunas comunidades autónomas, como la del País Vasco, han promovido la construcción de un importante parque público de vivienda. Los últimos treinta años los diversos Planes de Vivienda han permitido que parte del ahorro de los hogares se canalizase a la adquisición de una vivienda. Una manifestación de este proceso es el alto grado de vivienda en propiedad en la Comunidad Autónoma del País Vasco, comunidad con mayor índice de vivienda en propiedad, con el $85 \%$ y el menor número de pisos en alquiler, 15\%, durante 2017. Estos datos son muy superiores a los que encontramos en España: un $76,7 \%$ y un $23,3 \%$, respectivamente (Ministerio de Fomento, 2018).

La principal estrategia que siguió en Gobierno Vasco, como máximo responsable de las políticas de vivienda, se basó dos premisas. La primera, fue crear un marco normativo en el que a través del planeamiento se creaba una importante reserva de suelo público mediante recalificaciones, especialmente de viejo suelo industrial asociado a empresas públicas, localizado en las áreas centrales de la ciudad. La finalidad última era poder reducir el precio de la vivienda ${ }^{19}$.

La segunda fue la creación de un importante parque de vivienda protegida en propiedad, realizado a través de promociones públicas o privadas. Entre los años 2000-2016 se inició la construcción de 61.440 viviendas protegidas, de las cuales solo el 16,6\% fueron orientadas al alquiler (GoBIERNo VASco, 2017). El modo de acceso a este tipo de vivienda venía determinado por dos factores, principalmente. El primero de ellos, por la necesidad de reunir unos determinados requisitos; estar empadronado en algún municipio del País Vasco y tener un mínimo y un máximo de ingresos, según sea de régimen general o tasada, ${ }^{20}$ y no tener vivienda en

construcción de vivienda protegida, ya que obligaba a reservar el $65 \%$ del suelo para vivienda protegida cuando el suelo era de nueva urbanización y un $20 \%$ cuando el suelo era urbano en transformación. Posteriormente, estas reservas se fueron modificando como es el caso de la Ley del Suelo Autonómica del 2006, que llego a plantear una reserva de suelo para pisos protegidos de hasta el $70 \%$ del suelo urbanizable.

${ }_{20}$ Para más información relativa a los requisitos de acceso a la vivienda de protección oficial, ver: Etxebide 2020,

https://www.etxebide.euskadi.eus/promociones-de-etxebidepara-compra-y-alquiler-de-vivienda-protegida/x39-contgen/es/ 
propiedad. Una vez reunidos estos requisitos, la vivienda se adjudicaba mediante un sorteo. En caso de ser adjudicatario de una vivienda de protección, era necesaria la solicitud de un crédito bancario, y en el supuesto de no contar con un ingreso estable, se necesitaba un aval (normalmente un familiar cercano). Evidentemente, tras la crisis del 2008 este problema se agudizo, ya que era posible que se diera la situación de haber sido favorecido con la adjudicación de una vivienda por sorteo, pero no se podía acceder a la misma por falta de crédito bancario o de avales. Esta situación determinó en gran medida el perfil de quiénes podían realmente acceder a una vivienda pública ${ }^{21}$.

Un efecto colateral de esta estrategia ha sido el problema planteado con la descalificación de las viviendas de protección; esto supone que un importante patrimonio de viviendas públicas, pasaran a manos privadas en los próximos años. Las viviendas de protección oficial construidas antes del año 2003 se descalifican pasados veinte años ${ }^{22}$, una de cada tres viviendas construidas (32,5\%) (ETXEBIDE, 2019). En el caso de Bilbao se constituye un patrimonio

\begin{tabular}{lcccc} 
\% alquiler/total & $\begin{array}{r}\text { PDV } \\
\mathbf{2 0 0 2 -} \\
\mathbf{2 0 0 5}\end{array}$ & $\begin{array}{c}\text { PDV } \\
\mathbf{2 0 0 6 -} \\
\mathbf{2 0 0 9}\end{array}$ & $\begin{array}{c}\text { PDV } \\
\mathbf{2 0 1 0 -}\end{array}$ & $\begin{array}{c}\text { PDV } \\
\mathbf{2 0 1 2} \\
\mathbf{2 0 1 6}\end{array}$ \\
\hline $\begin{array}{l}\mathbf{N}^{\circ} \text { de Vivienda } \\
\text { de Protegidas } \\
\text { propuestas }\end{array}$ & 16.200 & 27.000 & 12.950 & 8.000 \\
\hline $\begin{array}{l}\text { Objetivo } \\
\text { Resultado }\end{array}$ & 45,1 & 31,5 & 33,2 & 49,4 \\
\hline
\end{tabular}

FIG. 13/ Grado de cumplimiento de los Planes de Vivienda: la cuota de alquiler sobre el parque protegido total.

Fuente: Gobierno VAsco. Dpto. de Medio Ambiente. Ordenación Territorial y Vivienda.

\footnotetext{
${ }^{21}$ El caso más paradójico nos lo encontramos en el caso de barrio de Miribilla, el mayor conjunto de viviendas de V.P.O que se realiza en Bilbao, en el año 2017 su renta familiar era de 49.018 euros cuando la renta media de la ciudad era de 42.805 euros.

${ }^{22}$ A partir del año 2003, se aplica la calificación permanente para las viviendas promovidas por el Gobierno Vasco, permitiendo que dicho parque permaneciera como patrimonio público.

${ }^{23}$ Decreto $466 / 2013$ de 23 de diciembre, que regula el Programa de Vivienda Vacía (Bizigune). El objetivo es captar pisos desocupados para su puesta en el mercado a través del alquiler protegido de forma voluntaria. La característica más importante es que los propietarios perciben aproximadamente el $65 \%$ de la renta mensual habitual en el mercado, y que los arrendatarios no abonen por la vivienda más del $30 \%$ de sus ingresos brutos anuales. La gestión de este programa de viviendas corresponde a la sociedad pública
}

significativo, $51,8 \%$ de las 4.620 viviendas protegidas (ETXEBIDE, 2019).

En cuanto a las viviendas en alquiler, tal como se reconoce en el Plan Director de Vivienda 2018-2020 (GoBIERNo VASCO, 2017: 37), el número de viviendas en alquiler que se construyeron, en los diferentes Planes Vivienda se situó muy por debajo de los objetivos previstos (FIG. 13). Se construyeron menos de la mitad de las viviendas previstas. Los más afectados por esta política fueron aquellos sectores de población que no tenían recursos para acceder una vivienda en propiedad.

Así mismo, la política de alquiler desarrollada desde el ámbito institucional se ha caracterizado por su fragmentación. Por una parte, el parque de vivienda público en alquiler se ha gestionado a través de Alokabide; por otra, se ha incentivando a los propietarios de viviendas vacías para que coloquen su vivienda en el mercado bajo la cobertura de Gobierno Vasco asegurándoles una tasa mínima de beneficio. Son los programas Bizigune ${ }^{23}$ y $\mathrm{ASAP}^{24}$, que consisten en unos programas de intermediación para que un propietario de vivienda privada se incorpore al mercado de la vivienda a cambio de un precio accesible para los arrendatarios ${ }^{25}$. Los resultados más bien han sido limitados: el programa Bizigune en el año 2018 había captado 5.325 viviendas ${ }^{26}$, el programa ASAP únicamente había captado 263 viviendas (ETXEBIDE, 2019: 39).

En el caso de Bilbao, el parque de vivienda ha crecido de forma importante: entre el año 20012017 se construyeron 14.756 vivienda (EUSTAT, 2018), de las cuales la mitad (7.514 viviendas) fueron Viviendas de Protección Oficial (VPO) (AYUNTAMIENTO DE BILBAO, 2018b). El impacto que ha tenido en la ciudad es significativo, creando barrios nuevos como Miribilla ${ }^{27}$ o amplios conjuntos como es el caso de La Mina del Morro,

Alokabide, dependiente de Gobierno Vasco creada para el desarrollo de la función social de la política de alquiler, bajo la dirección y control del Departamento correspondiente en materia de vivienda. Una de las características del programa es que los arrendatarios tienen que estar inscritos en el Servicio Vasco de Vivienda (ETXEBIDE)

${ }^{24}$ Decreto 180/2014 de 23 de septiembre.

25 Para eso se estableció una serie de garantías en forma de pólizas de seguros que cubre a las personas propietarias de impagos de su renta posibles desperfectos y asistencia jurídica a cambio de que las rentas no pasen una cuantía máxima.

${ }^{26}$ La renta media que se le paga al propietario es de 488,3 euros, la renta media que paga el arrendado es de 243 euros, la diferencia que es del $49,7 \%$ lo paga el Gobierno Vasco. 27 La mayor promoción de V.P.O. realizada en Bilbao se corresponde con el barrio de Miribilla, entre los años 2000 y 2003 se realizaron 1935 viviendas de V.P.O. 1.042 libres. 
o las Torre Roger en Basurto ${ }^{28}$. La intensidad constructiva ha sido variable en los diferentes períodos, pero sí se ha observado como a partir del año 2012 se ha producido una caída significativa. La etapa 2003-2005 fue el momento de mayor auge de este tipo de vivienda; en ese periodo de tiempo se terminó el $46,5 \%$ de parque existente, como resultado de las viviendas iniciadas en los años anteriores. La modalidad elegida ha sido fundamentalmente la vivienda protegida, la VPO, aunque a partir de 2012 empiezan a aparecer nuevas figuras, como las viviendas tasadas autonómicas y los alojamientos dotacionales $^{29}$. Con respecto al alquiler, una de las particularidades que se da en Bilbao es la existencia de un importante parque de vivienda en alquiler en manos de las administraciones públicas, especialmente del Ayuntamiento de Bilbao, que las gestiona a través de la empresa pública de Viviendas Municipales. En el año 2018, contaba con 4.149 viviendas arrendadas ${ }^{30}$ mientras que Gobierno Vasco contaba con 1.415 viviendas $^{31}$, a todas luces insuficientes para las necesidades demandadas $^{32}$.

En cuanto al precio de la vivienda en Bilbao, ha ido disminuyendo tanto la vivienda usada como nueva y por el contrario se ha dado un incremento de los alquileres. Esta caída hay que entenderla por la dificultad de acceder a los créditos al haberse vueltos más restrictivos, sobre todo a partir de la burbuja inmobiliaria del 2008 y por la precariedad laboral. Entre los años 2007 y 2018 la vivienda libre cae un $35 \%$ y la vivienda usada un $28,3 \%$. En cambio, los alquileres experimentan importantes crecimientos debido a su mayor rentabilidad. A ello ha contribuido la Ley de Arrendamientos Urbanos (2013) y el desarrollo de los apartamentos turísticos y por la demanda generada por aquellos colectivos que no pueden acceder a una nueva vivienda, normalmente tienen entre 25 y 30 años, ya que no cuentan con recursos estables suficientes.

\footnotetext{
${ }^{28}$ La iniciativa privada también promociono vivienda de V.P.O. dada su rentabilidad, actuando en Miribilla, en la Plaza del Gas o en el Fango. Así mismo, nos encontramos como organismos para-públicos como VISESA (organismo dependiente del Gobierno Vasco) o el propio Ayuntamiento de Bilbao a través del Programa de Viviendas Municipales.

${ }^{29}$ La Ley del suelo del País Vasco 2006 aparece por primera vez el concepto de "Alojamiento dotacional"

Son apartamentos de alquiler temporal barato para jóvenes y otros colectivos sociales, de carácter temporal con un máximo de 5 años, y cuya cuota incluye los gastos de los servicios. "Es una dotación residencial en parte de una construcción, que se destina a resolver de forma transitoria y mediante pago de renta o canon la necesidad de habitación de personas o unidades de convivencia". (BOPV Ley de $3 / 2015$, de 18 de junio 2015).

${ }^{30}$ Los perfiles de los usuarios de las viviendas municipales aportan datos de interés: son fundamentalmente persona
}

Desde el año 2013 se detecta una subida constante, pasando de 895,8 euros el precio del $\mathrm{m}^{2}$ a 1.084 euros en el año 2018 (OBSERVATORIO DE LOS BARRIOS DE BILBAO).

Actualmente, se admite que los alquileres están tocando techo en algunas zonas de la ciudad porque una familia teóricamente, no puede asumir un coste superior al $30 \%$ de los ingresos familiares. Si tomamos como referencia los precios de los alquileres y la renta familiar disponibles en los hogares de Bilbao, en base a la tipología de barrios realizada en el trabajo, nos encontramos que aquellos barrios con renta media-baja y baja es donde el impacto del alquiler es mayor, supondría entre el $26,4 \%$ el $31,5 \%$ de su renta disponible anual (FIG. 14).

En relación a las políticas de rehabilitación, consideramos necesario señalar que Bilbao tiene un parque de vivienda muy antiguo, el promedio es de 50 años, y presenta importante problemas estructuras $^{33}$. Hay barrios en el que más de $70 \%$ de los edificios no tiene ascensor, como son los casos de Altamira $(84,1 \%)$, Iturrigorri-Peñascal $(78,7 \%)$ o Arabella $(94,5 \%)$, que coinciden con aquellos barrios con las rentas más bajas de la ciudad (OBSERVATORIO URBANO DE BARRIOS DE BILBAO). En el año 1985 se creó la empresa pública municipal Surbisa, cuyo objetivo es incentivar la rehabilitación de los edificios del municipio. Su labor ha sido importante: solo entre los años 2006 al 2017 la inversión realizada ha sido de 75.535 euros en ayudas a la rehabilitación ${ }^{34}$. De los ocho barrios que están en el programa de Surbisa, cuatro de ellos tienen unas rentas familiares bajas y tres medias-bajas. Son barrios localizados en zonas degradadas en el área central de la ciudad en fase de transformación (Bilbao La Vieja, San Francisco, Zabala e Irala). Son barrios en los que más que a un proceso de gentrificación, se asiste a un proceso de reposición del parque de vivienda causado

que viven solas un $59,3 \%$, entre 35 y 55 años $55,8 \%$ y hombres $58,5 \%$ con unos ingresos entre 9.000 y 15.000 euros anuales. La demanda se ido incrementando en los últimos años especialmente a partir del 2014 que se ha pasado de 6.556 a 9.386 demandantes en el 2018 (VIVIENDAS MUNICIPALES, 2018: 13).

${ }^{31}$ Las gestionaba a través de los diversos programas como 685 viviendas de Alokabide, 706 del programa Bizigune y 25 viviendas de ASAP.

32 Solo la demanda prevista en el Plan de Vivienda 20182020, de Gobierno Vasco, para ese periodo en el Bilbao Metropolitana, hay una demandad de vivienda en alquiler de 23.417 viviendas (GoBIERNO VASCO, 2017: 115).

${ }^{33}$ El $62 \%$ de las viviendas (según los datos del censo del 2011) no son accesible. Según la definición del INE se entiende por vivienda no accesible aquella en la que una persona en silla de ruedas no podría acceder por sus propios medios. ${ }^{34}$ Ayuntamiento de Bilbao. Memoria de Surbisa 2018C. 


\begin{tabular}{|c|c|c|c|c|c|}
\hline Tipología & Tipo de renta & $\begin{array}{l}\text { Renta familiar } \\
\text { disponible }\end{array}$ & $\begin{array}{l}\text { Media de } \\
\text { alquiler } \\
\text { mensual }\end{array}$ & Anual & $\begin{array}{c}\% \text { de la renta } \\
\text { disponible dedicada } \\
\text { al alquiler }\end{array}$ \\
\hline Tipología 1 & Altas & 56.422 & 905,6 & $10.867,2$ & 19,2 \\
\hline Tipología 2 & Media-alta & 46.531 & $7.47,3$ & $8.967,6$ & 19,2 \\
\hline Tipología 3 & Media & 38.265 & $7.34,9$ & $8.818,8$ & 23,0 \\
\hline Tipología 4 & Media-baja & 29.417 & $6.49,0$ & $7.788,0$ & 26,4 \\
\hline Tipología 5 & Baja & 23.398 & $6.15,6$ & $7.387,2$ & 31,5 \\
\hline
\end{tabular}

FIG. 14/ \% de la renta familiar disponible de dedicada al alquiler del hogar (2017).

Fuente: elaboración propia: EUSTAT Estadística de las rentas personales y familiares. Ayuntamiento de Bilbao.

por el fallecimiento de las personas residentes mayores o por su trasladado a una residencia o casa de algún familiar, cuyas viviendas son ocupadas por una población más joven. Por otra parte, Surbisa también interviene en algunos barrios localizados en la periferia urbana (Otxarkoaga, Zorrotza, Olabeaga).

\section{Conclusión}

El periodo analizado, 2001 a 2017 , se caracteriza por el aumento de la desigualdad y la distancia social entre aquellos barrios con unas rentas altas y los barrios con rentas medias-bajas y bajas. En el año 2017, el $62 \%$ de la población tenía una renta inferior a la media de la ciudad, que era 42.805 euros anuales.

El salario o renta del trabajo, sigue siendo la fuente más importante de ingresos de los hogares, pero su protagonismo se va reduciendo a favor de las rentas de transferencias. En aquellos barrios con rentas altas las transferencias están orientadas fundamentalmente para el pago de pensiones y coinciden con aquellos barrios con la mayor tasa de envejecimiento. En cambio, en los barrios con renta media-baja o baja van orientadas para el subsidio de desempleo, ayudas sociales o el pago de la Renta Garantía de Inserción (RGI.).

Las familias que viven en barrios con renta alta tienden a diversificar sus ingresos familiares. Gran parte de sus ingresos provienen las rentas de capital, de los intereses y dividendos de sus ahorros financieros (cuentas a plazo fijo, acciones...) y en menor medida del cobro por alquileres y venta de bienes inmuebles; por lo tanto, del capital inmobiliario, en su conjunto, estos ingresos llegan hasta el $17 \%$. En los barrios con renta media-baja y baja estas rentas apenas tienen relevancia.

El proceso de transformación urbana de la ciudad, especialmente en el periodo transcurrido entre los años 2001 y 2009, coincidió con un importante incremento de la renta familiar disponible en el conjunto de la ciudad, pero de forma muy desigual. Los barrios con renta familiar alta crecieron tres veces más que los barrios con renta baja. La crisis económica, que en Bilbao empieza a manifestarse a partir del año 2010 , supuso una reducción del crecimiento de las mismas, aunque los barrios más desfavorecidos, se vieron favorecidos por el aumento de la RGI. En cualquier caso, en el año 2017 no se había recuperado la renta familiar que existía en el año 2009.

Las políticas de vivienda desarrolladas por el Gobierno Vasco en el periodo entre 2001 y 2017 fueron orientadas fundamentalmente a crear una base social de propietarios de clase media. Las políticas de alquiler tuvieron un impacto muy limitado desde un punto de vista de la promoción de vivienda pública. Aquellos sectores con necesidades dotacionales quedaron al margen, sobre todo a partir de la crisis del 2008. La Ley 3/2015 de Vivienda aprobada en el Parlamento Vasco supuso un profundo cambio de la política de vivienda, al reconocer el derecho subjetivo de la vivienda y hacer así del alquiler el nuevo eje de la promoción de vivienda pública.

Asistimos, por tanto, a la configuración de un modelo dual, donde la distancia entre los barrios con rentas altas y los barrios con rentas mediasbajas y bajas se ha incrementado a lo largo del periodo estudiado. Las transformaciones urbanas llevada a cabo en la ciudad en el periodo de 2001 a 2009 y la forma posterior de abordar la crisis no podrían haberse realizado sin una 
fuerte intervención del Estado; y esto, no es ni arquitectura, ni diseño.

En cuanto a los próximos años, y como consecuencia de la crisis económica provocada por la COVID19, será importante conocer las políticas públicas que se van a poner en marcha y, sobre todo, cuáles serán sus objetivos, ya que de ello dependerá que se profundice en este modelo de ciudad dual o se corrijan los desequilibrios en la ciudad de Bilbao.

\section{Bibliografía}

Argailan (2019): Perfil de la Renta Garantía de Ingresos por barrios. Argilan, 2019.

AyUNTAMIENTO DE BILbAo (2017): Diagnóstico de la vivienda vacía en Bilbao (Informe final). Ed. Ayto. de Bilbao, 2017.

- (2018): Licencias de edificación 2004-2017. Ed. Ayto. de Bilbao, 2018.

- (2018B): Memoria Viviendas Municipales 2018. Ed. Ayto. de Bilbao, 2018

- (2018c): Memoria de Surbisa 2018.

B.O.E.: Real Decreto-ley 7/2019, de 1 de marzo, de medidas urgentes en materia de vivienda y alquiler.

B.O.P.V. (Boletín de País Vasco): Decreto 466/2013 de 23 de diciembre, que regula el Programa de Vivienda Vacía (Bizigune).

- (Boletín de País Vasco): Decreto 180/2014, de 23 de septiembre, de modificación del Decreto por el que se crea el Programa de Intermediación en el Mercado de Alquiler de Vivienda Libre ASAP (Alokairu Segurua, Arrazoizko Prezioa).

- (Boletín del País Vasco): Ley de 3/2015, de 18 de junio 2015 sobre "Alojamientos dotacionales".

CASTELLS, M (1991): El auge de la Ciudad Dual: teoría social y tendencias sociales. Alfoz, n. ${ }^{\circ} 80$.

ETXEBIDE (2019a): Aproximación al impacto de la calificación permanente de la vivienda protegida en Euskadi. Ed. Gobierno Vasco. Vitoria/Gasteiz. https://www.etxebide.euskadi.eus/x39-ovad03/es/ contenidos/informacion/ovv desc/es ovv admi/ index.shtml

- (2019b): Informe de Evaluación Integral de las Políticas de Vivienda. 2018. Ed. Gobierno Vasco. Vitoria/Gasteiz, 2019.

https://www.etxebide.euskadi.eus/x39-ovad03/es/ contenidos/informacion/ovv pol2018/es ovv admi/ index.shtml

EUSTAT (INSTITUTO VASCO DE EsTAdístICA) (2018): Estadística Municipal, Bilbao 2001- 2017 vivienda. Gobierno Vasco. Vitoria / Gasteiz, 2018.

- (Instituto VAsco de Estadística (2019): Rentas personales y familiares. Barrios de Bilbao 2001-2017. GoBIERNO VASCO Vitoria / Gasteiz, 2019.

- (1994): LEY 17/1994, de 30 de junio, de medidas urgentes en materia de vivienda y de tramitación de los instrumentos de planeamiento y gestión urbanística.

- (2015): Ley 3/2015, de 18 de junio de Vivienda.

DPTO. DE MEDIO AMBIENTE, PLANIFICACIÓN TERRITORIAL Y VIVIENDA DEL GobIERNO VASCO (2017): Plan de Vivienda 2018-2020. Ed. Gobierno Vasco. Ed Gobierno Vasco. Vitoria /Gasteiz, 2017.

INE (2019): Encuesta de Condiciones de Vida, 2019.

- (2007): Encuesta de Población Activa (E.P.A). Datos correspondientes a Bilbao, 2007.

- (2017): Encuesta de Población Activa (E.P.A). Datos correspondientes a Bilbao, 2017.

MONTERA34 (2017): https://lab.montera34.com/airbnb/barrios/euskalherrial

MERTON R.K. (2002): Teoría y estructuras sociales. Fondo de Cultura Económica, Mexica, 2002.

MINISTERIO DE FOMENTO (2018): Observatorio de Vivienda y Suelo. Alquiler residencial. Ed. Ministerio de Fomento. Madrid, 2018.

ObSERVATORIo URBANo de BARRIOS DE BILBAo (2013): https://www.bilbao.eus/cs/Satellite?c=Page \&cid=3 010935570\&language $=$ es\&pageid $=3010935570$ \& pagename=Bilbaonet $\% 2 \mathrm{FPage} \% 2 \mathrm{FBIO}$ contenidoFinal 